\title{
EUS-B-FNA for Diagnosing Liver and Celiac Metastases in Lung Cancer Patients
}

\author{
Ida Skovgaard Christiansen ${ }^{a, b}$ Uffe Bodtger ${ }^{a-c}$ Therese Maria Henriette Naur ${ }^{b}, d$ \\ Khaliq Ahmad ${ }^{b}$ Jatinder Singh Sidhu ${ }^{b}$ Rafi Nessar ${ }^{a}$ Goran Nadir Salih ${ }^{a}$ \\ Asbjørn Høegholmb Jouke Tabe Annema ${ }^{\mathrm{e}}$ Paul Frost Clementsen ${ }^{\mathrm{a}, \mathrm{d}, \mathrm{f}}$ \\ a Unit of Respiratory Medicine, Department of Internal Medicine, Zealand University Hospital, Roskilde, Denmark; \\ ${ }^{b}$ Department of Respiratory Medicine, Næstved Hospital, Næstved, Denmark; ' Institute for Regional Health \\ Research, University of Southern Denmark, Odense, Denmark; ${ }^{d}$ Copenhagen Academy for Medical Education and \\ Simulation (CAMES), Capital Region of Denmark, Copenhagen, Denmark; ${ }^{e}$ Department of Respiratory Medicine, \\ AMC, Amsterdam University Medical Centers, Amsterdam, The Netherlands; ${ }^{f}$ Department of Clinical Medicine, \\ University of Copenhagen, Copenhagen, Denmark
}

\section{Keywords}

Lung cancer · EBUS · EUS · EUS-B · Metastases · Liver ·

Retroperitoneum

\begin{abstract}
Background: In patients with suspected or proven lung cancer, assessment of regional nodal and distant metastases is key before treatment planning. By introducing the endobronchial ultrasound (EBUS)-guided scope into the esophagus and stomach (EUS-B), liver lesions and celiac nodes can be visualized. To date, the utility of EUS-B in diagnosing liver lesions and retroperitoneal lymph nodes is unknown. Objectives: To assess the feasibility, safety, and diagnostic yield of sampling of liver lesions and retroperitoneal nodes by EUS-B fine-needle aspiration (FNA) in a lung cancer staging setting. Method: Consecutive patients suspected of lung cancer in 2 Danish centers between 1 January 2015 and 31 December 2017 were included retrospectively when a lesion in the liver or a retroperitoneal lymph node was visualized and biopsied with EUS-B-FNA. Results: 23 left liver lobe lesions and 19 retroperitoneal lymph nodes were sampled by EUS-B-FNA. Sen-
\end{abstract}

sitivity and diagnostic yield of sampled liver lesions were 86 and $83 \%$, respectively. In 19/23 patients, there was a cytopathological diagnosis of malignancy. Sensitivity and diagnostic yield from retroperitoneal lymph node samples were 83 and $63 \%$, respectively. In 10/19 patients, the diagnosis was malignancy. No complications were observed. Conclusion: EUS-B-FNA enables safe sampling of left liver lobe lesions and retroperitoneal lymph nodes. EUS-B should be considered as a minimally invasive technique to provide tissue proof of distant metastases lung cancer patients.

\footnotetext{
(c) 2019 The Author(s)

Published by S. Karger AG, Basel
}

\section{Introduction}

In patients with non-small-cell lung cancer (NSCLC), accurate staging [1] is crucial for treatment allocation, especially for surgical lung tumor resection which is curative only in cases of localized disease. Therefore, it is mandatory to exclude metastases both in the mediastinum and below the diaphragm before the treatment deci-

\begin{tabular}{|c|c|}
\hline KARGER & $\begin{array}{l}\text { (c) } 2019 \text { The Author(s) } \\
\text { Published by S. Karger AG, Basel }\end{array}$ \\
\hline $\begin{array}{l}\text { E-Mail karger@karger.com } \\
\text { www.karger.com/res }\end{array}$ & $\begin{array}{l}\text { This article is licensed under the Creative Commons Attribution- } \\
\text { NonCommercial-NoDerivatives } 4.0 \text { International License (CC BY- } \\
\text { NC-ND) (http://www.karger.com/Services/OpenAccessLicense). } \\
\text { Usage and distribution for commercial purposes as well as any dis- } \\
\text { tribution of modified material requires written permission. }\end{array}$ \\
\hline
\end{tabular}

Jouke Tabe Annema

Department of Respiratory Medicine, AMC, Amsterdam University Medical Centers Meibergdreef 9, 1105

NL-1105 Amsterdam (The Netherlands)

E-Mail j.t.annema@amc.nl 
sion. Endobronchial ultrasound-guided transbronchial needle aspiration (EBUS-TBNA) and endoscopic esophageal ultrasound-guided fine-needle aspiration (EUSFNA) have high accuracy for demonstrating lymph node metastases in the mediastinum $[2,3]$. In the case of suspicious lesions below the diaphragm, abdominal ultrasound with percutaneous biopsy is the most often used technique to confirm or invalidate the suspicion. An alternative, especially in difficult-to-reach lesions is EUSFNA, which has been demonstrated to establish tissue verification from suspected lesions in the liver, the left adrenal gland, and the abdominal lymph nodes in lung cancer patients [4-6]. However, very few pulmonologists perform conventional gastrointestinal EUS-FNA, whereas the use of the EBUS scope in the esophagus (i.e., EUSB-FNA) is quickly gaining ground [2]. EUS-B-FNA is useful as a supplement to an endobronchial approach for additional sampling of mediastinal nodes [7-9]. To perform optimal mediastinal nodal staging, it is recommended that the mediastinal nodal EBUS examination is complemented by either EUS-FNA or EUS-B-FNA [2]. A retrospective study demonstrated that for mediastinal staging, EUS-B was faster, patients needed less sedation and oxygen, and the time to discharge was shorter than with EBUS, but that the diagnostic yield was the same [10].

With regard to lesions below the diaphragm, in the European guidelines for combined EBUS and EUS, EUSFNA is recommended for tissue verification from left adrenal gland lesions suspected of metastases [2]. However, the guidelines do not mention suspicious lesions other than the left adrenal gland. This reflects that EUS-B-FNA is a relatively novel technique and that the literature consequently gives us limited access to experience. With this background, we decided to investigate if lesions in the liver and retroperitoneal lymph nodes could be visualized and sampled by EUS-B-FNA in a lung cancer staging setting.

\section{Methods}

In 2 centers (the Unit of Respiratory Medicine, Department of Internal Medicine, Zealand University Hospital, Roskilde, and the Department of Respiratory Medicine, Næstved Hospital, Næstved, in Denmark), we performed a retrospective endosonography database search with the following inclusion criteria: (a) known or suspected lung cancer, (b) referral between 1 January 2015 and 31 December 2017, and (c) a lesion in the liver or a retroperitoneal lymph node was visualized and subsequent biopsy with EUS-BFNA was attempted.

EUS-B-FNA for Diagnosing Liver and

Celiac Metastases in Lung Cancer Patients

\section{Standard of Reference}

EUS-B fine-needle aspirates were considered adequate when cells from target tissue (liver: hepatocytes; celiac nodes: lymphocytes) or malignant cells were demonstrated in the sample. Samples with malignant cells were considered as true-positive.

For adequate samples with nonmalignant diagnoses at cytopathological evaluation, the results were considered true-negative if verified at a follow-up of least 6 months (clinical course possibly supplemented with computed tomography [CT]).

Diagnostic yield was defined as the number of samples in which EUS-B-FNA provided a specific diagnosis (malignant or nonmalignant) relative to the total number of EUS-B-FNA samples [11]. Sensitivity was defined as the number of samples in which EUS-BFNA provided a diagnosis of any malignancy relative to the total number of targeted lesions that turned out to be malignant [11]. Sensitivity was calculated as the "worst-case" scenario in which all patients with inconclusive samples or no follow-up were considered as suffering from malignant disease.

Patients in whom the suspicion of lung cancer was invalidated after complete workup were followed for 6 months to identify false-negative cases. Data were nonparametric and presented as median and range. Data were processed using SPSS v25 (IBM, Chicago, IL, USA).

\section{The EUS-B Procedure}

Initially, a bronchoscopy and an EBUS procedure according to a structured protocol as described by Konge et al. [12] and Jenssen et al. [13] were performed with the patient lying on their back under conscious sedation. Either a nasal or an oral approach was used. Thereafter, the EBUS endoscope was retracted from the trachea to a level just above the vocal cords, and from this position turned slightly to the left and the back of the patient and advanced into the esophagus under gentle pressure while the patient was encouraged to swallow. Continuous ultrasound imaging was performed, and the endoscope was advanced very carefully without pressure to a level below the diaphragm. Five milliliters of $4 \% \mathrm{Li}$ docaine was applied to the pharynx and larynx prior to the EUS-B procedure to make it easier to introduce the endoscope in the esophagus. The left liver lobe was searched for by turning the transducer to the right side of the patient below the diaphragm. The hepatic veins were visualized with Doppler and the left liver lobe was swept for suspicious lesions. The abdominal aorta and the celiac trunk were identified and the search was expanded to detect enlarged retroperitoneal lymph nodes.

A structured protocol was followed using an EUS assessment tool (EUS-AT) [12-14] with 6 landmarks identified in this order: the liver, abdominal aorta, left adrenal gland, lymph node station 7 , and stations $4 \mathrm{~L}$ and $4 \mathrm{R}$. This validated and systematic tool is specifically developed for the examination of lung cancer patients. Furthermore, structures not included in the EUS-AT were searched for and visualized when $\mathrm{CT}$ and/or positron emission tomography (PET)-CT showed these to be abnormal [12-14].

When a target lesion was located, the needle was introduced through the biopsy channel of the endoscope. Power Doppler was used to prevent the puncture of vessels. The needle was placed in the lesion under real-time ultrasonic guidance and the stylet was then removed. Suction was applied with a syringe and the needle was moved back and forth inside the lesion. At least 2 samples were taken from each structure biopsied and the aspirates were processed for both cytological smears and cell block analysis. 
Table 1. Demographic data and diagnosis after complete workup

\begin{tabular}{lll}
\hline & Liver & $\begin{array}{l}\text { Retro- } \\
\text { peritoneal } \\
\text { lymph nodes }\end{array}$ \\
& & \\
\hline $\begin{array}{l}\text { Demographics } \\
\text { Total number of patients }\end{array}$ & 23 & 19 \\
Male gender & $12(52)$ & $8(42)$ \\
Median age (range), years & $72(48-85)$ & $73(42-80)$ \\
\hline Final diagnosis after complete workup & & \\
Primary pulmonary cancer: & & \\
NSCLC & $5(22)$ & $2(11)$ \\
$\quad$ Adenocarcinoma & $5(22)$ & $1(5)$ \\
Squamous cell carcinoma & $6(26)$ & $1(5)$ \\
SCLC & $2(9)$ & 0 \\
Large-cell neuroendocrine carcinoma & & \\
Metastasis from extrapulmonary tumor & $4^{\mathrm{a}}(17)$ & $2^{\mathrm{b}}(11)$ \\
Malignant lymphoma & 0 & $6(32)$ \\
Nonmalignant & $1(4)$ & $7(37)$ \\
\hline
\end{tabular}

Values express $n$ (\%), unless otherwise indicated. ${ }^{a}$ Upper gastrointestinal tract: 2 ; colon: 1 ; pancreas: $1 .{ }^{\mathrm{b}}$ Malignant melanoma: 1, pancreas: 1 . NSCLC, non-small cell lung cancer; SCLC, small cell lung cancer.

Table 2. Cytopathological results of samples from 23 liver lesions

\begin{tabular}{lc}
\hline Size of lesion on $\mathrm{CT}^{\mathrm{a}}, \mathrm{mm}$ & $21(9-44)$ \\
Adequate samples $^{\mathrm{b}}$ & $21(91.3)$ \\
Diagnosis from adequate samples & \\
Malignancy & $19(90.5)$ \\
Nonmalignant & $2(9.5)$ \\
\hline
\end{tabular}

Values express $n$ (\%) or median (range). ${ }^{\text {a }}$ Long-axis diameter. ${ }^{\mathrm{b}}$ Samples were considered adequate when they displayed liver cells or malignant cells.

Table 3. Cytopathological results of samples from 19 retroperitoneal lymph nodes

\begin{tabular}{lc}
\hline Size of lesion on $\mathrm{CT}^{\mathrm{a}}, \mathrm{mm}$ & $18(9-65)$ \\
Adequate samples $^{\mathrm{b}}$ & $19(100)$ \\
Diagnosis from adequate samples & \\
Malignancy & $10(53)$ \\
Nonmalignant & $9(47)$ \\
\hline
\end{tabular}

Values express $n(\%)$ or median (range). ${ }^{\text {a }}$ Long-axis diameter. b Samples were considered adequate when they displayed lymphocytes or malignant cells.
After the procedure, all patients were observed for $2 \mathrm{~h}$ before discharge. They were instructed to contact the departments if they experienced any kind of complications. Occurrence of complications would be noted in the patient record.

The pulmonologists were trained according to the apprenticeship principle and instructed by 2 experienced operators in how to search for structures both above and below the diaphragm in a systematic way [13]. No EUS-B simulator is available on the market yet.

\section{Equipment}

EUS-B was performed with a flexible ultrasound bronchoscope (Olympus BF-UC180F or UC 180F, Olympus Medical Systems Europe, Ltd., Hamburg, Germany) in combination with a Hitachi ultrasound scanner with a linear scanning transducer (EUB 6500 or Hivision Preirus, model EZU-MT28-S1) with the patient in the supine position during the investigation. A 19-gauge or 22-gauge needle was used for the aspirations (ViziShot Flex 19-gauge and 22-gauge Olympus ViziShot and ViziShot 2; Olympus Medical Systems Europe, Ltd. and Cook, Limerick, Ireland).

\section{Results}

A total of 23 samples from liver lesions and 19 from retroperitoneal lymph nodes were identified in $42 \mathrm{pa}$ tients. Demographics and final diagnosis after complete workup are shown Table 1. No patients with a final nonmalignant diagnosis developed cancer during the 6-month follow-up period. No complications linked to EUS-B procedures were observed. Of the 23 patients with samples from liver lesions, 1 had a final diagnosis of nonmalignant origin (sarcoidosis) and underwent a 6-month clinical follow-up without a diagnosis of cancer. Of the 19 patients with samples from retroperitoneal lymph nodes, 7 had a nonmalignant diagnosis (followed with clinical course: $n=4$; clinical course and CT: $n=3$ ) of: unspecific changes $(n=3)$, infectious $(n=2)$, and sarcoidosis $(n=2)$.

It was feasible to sample the liver lesion under realtime ultrasound control. Twenty-one of 23 (91\%) were adequate (contained hepatocytes) at cytopathological evaluation (Table 2). Malignancy was diagnosed in 19 samples, i.e., there was a diagnostic yield of $83 \%(19 / 23)$. Mostly, ultrasound characteristics of liver metastases showed hypoechoic round lesions. Of the 2 nonmalignant lesions, 1 was followed for 6 months and the nonmalignant result was confirmed. Follow-up of the lesions in the other patient with a nonmalignant finding and the 2 patients with inadequate samples was not possible due to disseminated malignancy and subsequent systemic oncological therapy. Thus, sensitivity of malignancy was $86 \%$ in the worst-case scenario (19 malignant/[19 malignant 

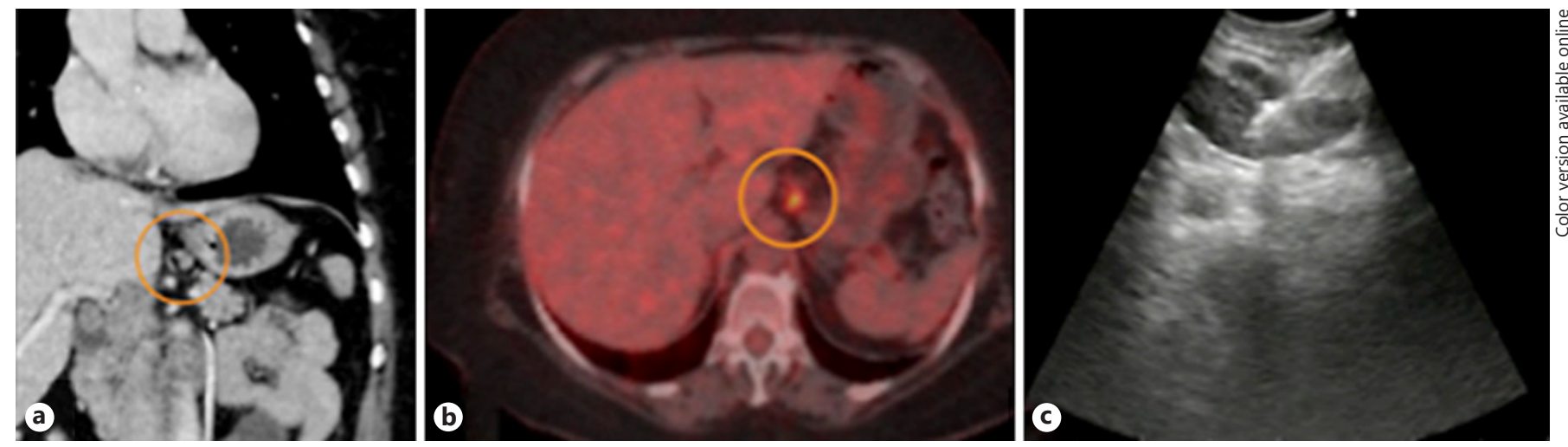

Fig. 1. A patient with cough presented with a celiac retroperitoneal lymph node $12 \times 15 \mathrm{~mm}$ in size. Cytological examination showed lymphatic tissue, nonnecrotizing granulomas, and no malignant cells. Similar results were obtained with EUS-B-FNA and EBUS-TBNA from station 7 and EBUS-TBNA from station 11L.
Granuloma detection was in line with a final diagnosis of sarcoidosis. a CT image of a celiac retroperitoneal lymph node marked with the orange circle. $\mathbf{b}$ PET-CT image showing the lymph node. c EUS-B image of the lymph node with the needle in.
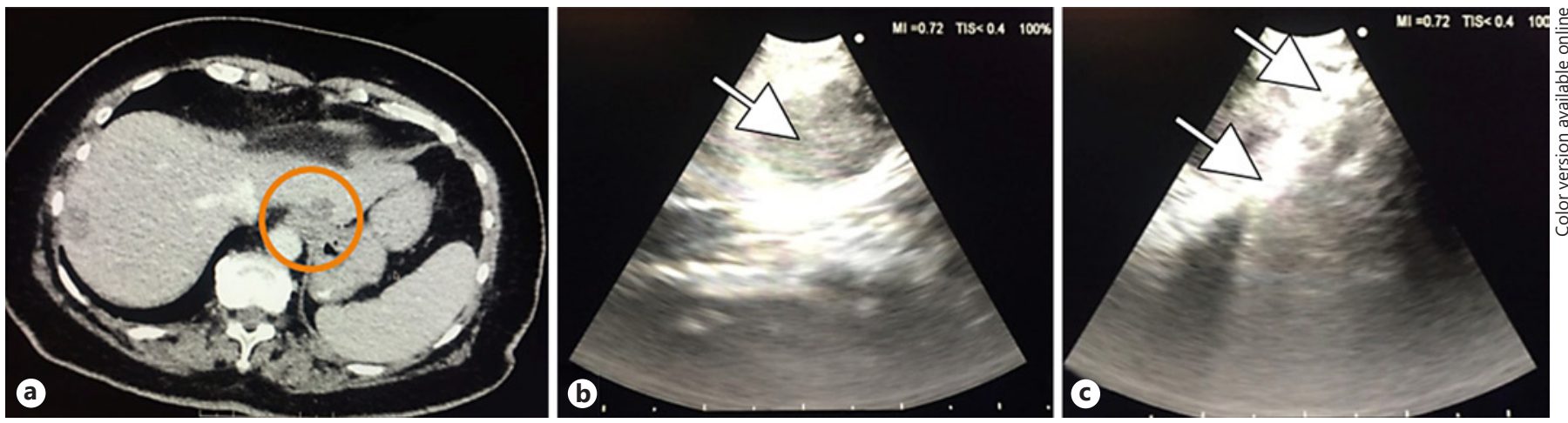

Fig. 2. A 77-year-old patient with no previous cancer presented with brain metastasis and suspicious lesions in the left adrenal gland, mediastinal lymph nodes, and liver. EBUS-FNA and EUSB-FNA were performed. Cytopathological evaluation of material from the left liver lobe showed malignant melanoma (PDL1-posi-

and 3 samples without follow-up]). All aspirated lesions were located in the left liver lobe.

All 19 samples (100\%) from the retroperitoneal lymph nodes were adequate for cytopathological evaluation (Table 3). Ten samples received a diagnosis of malignancy and 2 showed nonnecrotizing granulomas consistent with sarcoidosis. There was a diagnostic yield of $63 \%$ $(12 / 19)$.

For the 9 samples with a final nonmalignant diagnosis, 6-month follow-up was performed in 7 patients (clinical course: $n=3$, clinical course and CT: $n=4$ ) without a diagnosis of cancer. Follow-up was not possible in the other 2 due to disseminated malignancy and subsequent sys-

EUS-B-FNA for Diagnosing Liver and Celiac Metastases in Lung Cancer Patients tive $>50 \%$ ), but all other biopsies were benign. a CT image of 2 suspected metastatic tumors in the liver; the tumor biopsied with EUS-B-FNA is marked with a circle. $\mathbf{b}$ EUS-B image of the tumor, marked with a white arrow. c EUS-B image of the tumor with the needle in (needle marked with white arrows). temic oncological therapy. Thus, sensitivity of malignancy was $83 \%$ in the worst-case scenario (10 malignant/[ 10 malignant and 2 samples without follow-up]).

See Figure 1 and Figure 2 for case examples.

We present the first patient cohort showing that it is feasible and safe to sample live lesions and celiac nodes by EUS-B-FNA. These findings are important as we demonstrate that, with the EBUS scope routinely used for mediastinal nodal staging for lung cancer, lesions suspected for

\section{Discussion}


left live lobe metastases can be analyzed. In the hands of a skilled operator, mediastinal, liver, and celiac staging can be performed in a single endoscopy session.

So far, the use of EUS-B below the diaphragm has almost exclusively been used for the analysis of the left adrenal gland. Only very limited literature addresses the potential role of EUS-B in providing tissue proof of lesions below the diaphragm and thus attributing to diagnosing $\mathrm{M} 1 \mathrm{~b}$ and M1c disease. The left adrenal gland has been visualized and biopsied with EUS-B $[15,16]$. Crombag and Annema [16] found that the success rate of EUS-B-FNA of the left adrenal gland was comparable to conventional EUS-FNA. Adrenal masses are found in up to $7 \%$ of patients with potentially resectable lung cancer [17]. Approximately two-thirds of these masses are benign adenomas [18]. It has been shown that the left liver lobe [19] and retroperitoneal lymph nodes can be reached with EUS-B-FNA [20]. The incidence of liver metastases has been found to be $17.5 \%$ in SCLC patients and 3.8\% in NSCLC patients [21]. It is essential to confirm or invalidate the suspicion of M1 disease in these structures with tissue proof. The literature gives us no insight with respect to the accessibility to retroperitoneal lymph nodes with EUS-B and the clinical importance of this.

Traditionally, a percutaneous ultrasound-guided biopsy is performed when CT and PET-CT reveal suspicious lesions below the diaphragm [22]. It cannot be excluded, that some of the liver metastases biopsied in our study could have been reached with a percutaneous liver biopsy. However, in some cases, the distance from the transducer to the target may be shorter when performing EUS-B than with a percutaneous biopsy. The left liver lobe is accessible from the stomach and the right lobe from the duodenum $[4,23]$. In our study, all sampled liver lesions were located in the left liver lobe and the samples were obtained from the stomach.

In the newest guidelines on the use of EUS, it is recommended [6] that EUS-FNA of liver lesions suspected of malignancy be performed (with the conventional gastroenterologic endoscope) when the suspected liver lesion cannot be reached percutaneously. However, all of our patients had the EUS-B biopsy performed in the same session as EBUS, which has obvious practical advantages over performing endosonography and percutaneous biopsy in separate sessions.

One of the most important complications of liver biopsy is bleeding, with an incidence of $0.016 \%$ [24]. Infectious complications are considered rare in both percutaneous and endoscopic ultrasound-guided biopsies [5, 25]. No clear recommendations on administering pro- phylactic antibiotics in connection with EUS-FNA of liver lesions seem to exist, but antibiotics may be considered in connection with biopsy from pancreatic lesions [6]. No complications were seen in our study.

There are obvious logistical and practical advantages to performing an endosonography staging procedure with just 1 EBUS endoscope (EBUS + EUS-B) instead of 2 (EBUS + conventional EUS). In the diagnosis and staging of the patient with lung cancer, performing a mediastinal nodal evaluation by both the EBUS and EUS-B procedures in combination is advised in order to achieve optimal results [2].

Though inclusion in this study was consecutive, a limitation was a selection bias due to the retrospective design. Subsequent studies should include larger cohorts in a prospective multicenter design including exclusively consecutive patients.

Another limitation should be kept in mind, i.e., that a negative result in a biopsy always yields the risk of a falsenegative result. In this study, biopsies with negative results had a clinical follow-up of 6 months in cases where image control was not deemed relevant. However, potentially, the proportion of false-negatives could have been underestimated with this approach.

A strength of this study is that it contributes to the knowledge of the usefulness of the EUS-B-FNA technique in the hands of the pulmonologist. It has shown that structures that the literature has rarely described before as attainable with this technique can be biopsied.

Our results underline that EUS-B enables the pulmonologist to biopsy lesions below the diaphragm and that the technique is of diagnostic value in the combined endobronchial and esophageal diagnosing and staging of lung cancer [2]. Importantly, we show that EUS-B provides tissue proof of potential M1 lesions below the diaphragm from both liver lesions and retroperitoneal lymph nodes.

The novel insight is that EUS-B-FNA is a technically feasible and safe procedure that gives the pulmonologist access to the left liver lobe and retroperitoneal lymph nodes in the diagnosis and staging of patients suspected of lung cancer.

\section{Statement of Ethics}

The study was a retrospective observational study without experimental procedures and did not fall under the jurisdiction of the scientific ethics system. The study was approved by the Danish Data Protection Agency. 


\section{Disclosure Statement}

The authors declare that they have no conflicts of interest with respect to the content of this paper.

\section{Funding Sources}

This research did not receive any specific grant from funding agencies in the public, commercial or not-for-profit sectors.

\section{References}

1 Detterbeck FC, Boffa DJ, Kim AW, Tanoue LT. Lung Cancer Stage Classification. 8th ed. Chest. 2016;151:193-203.

2 Vilmann P, Frost Clementsen P, Colella S, Siemsen M, De Leyn P, Dumonceau JM, et al. Combined endobronchial and esophageal endosonography for the diagnosis and staging of lung cancer: European Society of Gastrointestinal Endoscopy (ESGE) Guideline, in cooperation with the European Respiratory Society (ERS) and the European Society of Thoracic Surgeons (ESTS). Eur J Cardiothorac Surg. 2015 Jul;48(1):1-15.

3 Vilmann P, Annema J, Clementsen P. Endosonography in bronchopulmonary disease. Best Pract Res Clin Gastroenterol. 2009;23(5): $711-28$.

4 Polkowski M, Larghi A, Weynand B, Boustière C, Giovannini M, Pujol B, et al.; European Society of Gastrointestinal Endoscopy (ESGE). Learning, techniques, and complications of endoscopic ultrasound (EUS)-guided sampling in gastroenterology: European Society of Gastrointestinal Endoscopy (ESGE) Technical Guideline. Endoscopy. 2012 Feb;44(2): 190-206.

5 Jenssen C, Hocke M, Fusaroli P, Gilja OH, Buscarini E, Havre RF, et al. EFSUMB Guidelines on Interventional Ultrasound (INVUS), Part IV - EUS-guided interventions: General Aspects and EUS-guided Sampling (Short Version). Ultraschall Med. 2016 Apr;37(2): 157-69.

6 Dumonceau JM, Deprez PH, Jenssen C, Iglesias-Garcia J, Larghi A, Vanbiervliet G, et al. Indications, results, and clinical impact of endoscopic ultrasound (EUS)-guided sampling in gastroenterology: European Society of Gastrointestinal Endoscopy (ESGE) Clinical Guideline - Updated January 2017. Endoscopy. 2017 Jul;49(7):695-714.

7 Hwangbo B, Lee HS, Lee GK, Lim KY, Lee SH, Kim HY, et al. Transoesophageal needle aspiration using a convex probe ultrasonic bronchoscope. Respirology. 2009 Aug;14(6):8439.

EUS-B-FNA for Diagnosing Liver and

Celiac Metastases in Lung Cancer Patients
8 Herth FJ, Krasnik M, Kahn N, Eberhardt R, Ernst A. Combined endoscopic-endobronchial ultrasound-guided fine-needle aspiration of mediastinal lymph nodes through a single bronchoscope in 150 patients with suspected lung cancer. Chest. 2010 Oct;138(4): 790-4.

9 Oki M, Saka H, Ando M, Tsuboi R, Nakahata M, Oka S, et al. Transbronchial vs transesophageal needle aspiration using an ultrasound bronchoscope for the diagnosis of mediastinal lesions: a randomized study. Chest. 2015 May;147(5):1259-66.

10 Meena N, Bartter T. Endosonography for mediastinal disease: esophageal ultrasound vs. endobronchial ultrasound. Endosc Int Open. 2015 Aug;3(4):E302-6.

11 Korevaar DA, Colella S, Spijker R, Bossuyt PM, Konge L, Clementsen PF, et al. Esophageal Endosonography for the Diagnosis of Intrapulmonary Tumors: A Systematic Review and Meta-Analysis. Respiration. 2017;93(2): 126-37.

12 Konge L, Clementsen PF, Ringsted C, Minddal V, Larsen KR, Annema JT. Simulator training for endobronchial ultrasound: a randomised controlled trial. Eur Respir J. 2015;4: $1140-9$.

13 Jenssen C, Annema JT, Clementsen P, Cui XW, Borst MM, Dietrich CF. Ultrasound techniques in the evaluation of the mediastinum, part 2: mediastinal lymph node anatomy and diagnostic reach of ultrasound techniques, clinical work up of neoplastic and inflammatory mediastinal lymphadenopathy using ultrasound techniques and how to learn mediastinal endosonography. J Thorac Dis. 2015 Oct;7(10):E439-58.

14 Konge L, Vilmann P, Clementsen P, Annema JT, Ringsted C. Reliable and valid assessment of competence in endoscopic ultrasonography and fine-needle aspiration for mediastinal staging of non-small cell lung cancer. Endoscopy. 2012 Oct;44(10):928-33.

15 Crombag LM, Szlubowski A, Stigt JA, Schuurbiers O, Korevaar DA, Bonta PI, et al. EUS-BFNA vs. conventional EUS-FNA for left adrenal gland analysis in lung cancer patients. Lung Cancer. 2017 Jun;108:38-44.
16 Crombag LM, Annema JT. Left Adrenal Gland Analysis in Lung Cancer Patients Using the Endobronchial Ultrasound Scope: A Feasibility Trial. Respiration. 2016;91(3): 235-40.

17 Chapman GS, Kumar D, Redmond J 3rd, Munderloh SH, Gandara DR. Upper abdominal computerized tomography scanning in staging non-small cell lung carcinoma. Cancer. 1984 Oct;54(8):1541-3.

18 Ettinghausen SE, Burt ME. Prospective evaluation of unilateral adrenal masses in patients with operable non-small-cell lung cancer. J Clin Oncol. 1991 Aug;9(8):1462-6.

19 Fally M, Nessar R, Behrendt N, Clementsen PF. Endoscopic Ultrasound-Guided Liver Biopsy in the Hands of a Chest Physician. Respiration. 2016;92(1):53-5.

20 Leong P, Deshpande S, Irving LB, Bardin PG, Farmer MW, Jennings BR, et al. Endoscopic ultrasound fine-needle aspiration by experienced pulmonologists: a cusum analysis. Eur Respir J. 2017 Nov;50(5):1701102.

21 Kagohashi K, Satoh H, Ishikawa H, Ohtsuka M, Sekizawa K. Liver metastasis at the time of initial diagnosis of lung cancer. Med Oncol. 2003;20(1):25-8.

22 Rockey DC, Caldwell SH, Goodman ZD, Nelson RC, Smith AD; American Association for the Study of Liver Diseases. Liver biopsy. Hepatology. 2009 Mar;49(3):1017-44.

23 Parekh PJ, Majithia R, Diehl DL, Baron TH. Endoscopic ultrasound-guided liver biopsy. Endosc Ultrasound. 2015 Apr-Jun;4(2):8591.

24 McGill DB, Rakela J, Zinsmeister AR, Ott BJ. A 21-year experience with major hemorrhage after percutaneous liver biopsy. Gastroenterology. 1990 Nov;99(5):1396-400.

25 Piccinino F, Sagnelli E, Pasquale G, Giusti G, et al. Complications following percutaneous liver biopsy. A multicentre retrospective study on 68,276 biopsies. J Hepatol. 1986; 2(2):165-73. 